\title{
THE IMAGE OF IRAQI POLITICS IN EDITORIAL CARTOONS
}

\section{A SEMIOTIC ANALYSIS}

\author{
Dr. Khalida H. Alghezzy
}

Dept. of Translation/ Faculty of Arts/ Wasit University/ kkhashoosh@uowasit.edu.iq

\begin{abstract}
This study analyzes a set of political cartoons created by Iraqi cartoonists. It sheds light on how these cartoons can function as mediators of meanings between the cartoonists and the readers. Moreover, the study attempts to prove the role of Iraqi cartoons in portraying the surrounding circumstances, especially political events, and examining their role in reflecting the main issues that exist in our daily life. Each of the cartoons includes the following content: financial and administrative corruption, power abuse, government promises and procrastination, and electricity failure. In short, this study demonstrates the role of political cartoons in affecting the reader's beliefs and attitudes.
\end{abstract}

Key Words: political cartoons, Cartoonist, Iraqi citizen, Corruption, Signifiers.

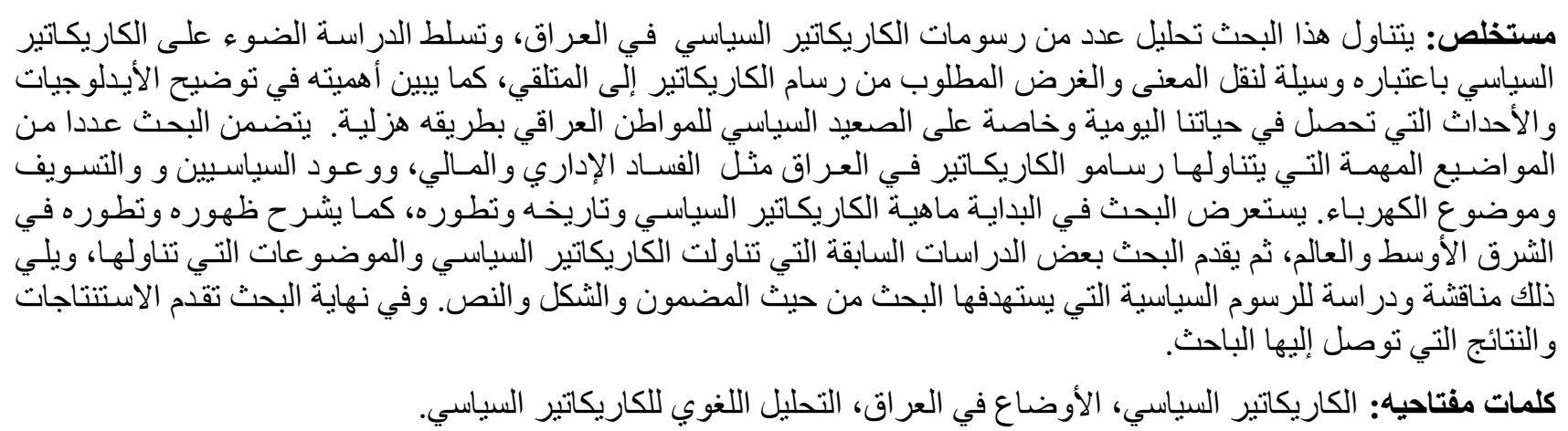

\section{Introduction}

Cartoons are " pictures as the essence of truth, messages as to what ought to be done, and moods created through artistic techniques and allegorical imageries of how the viewers ought to feel over what is happening " Press(1981: 62). Generally speaking, there are various forms of cartoons, such as political, social and humorous cartoons. These different forms have different functions. The important roles of political cartoons lie in making real changes in the society in favor of suppressed classes through criticizing the status quo and unjust practices in political life. Thus, political cartoons have the mechanism to correct the negatives of a society faster than written words, and are easily more received by readers. Political cartoons play significant role in shaping public opinion about various issues on a daily basis. Such political cartoons seek to influence public opinion through their use of widely understood symbols, slogans and allusions. The most obvious aspect in political cartoons is their ability to simplify the complex events of the day. They are designed to convey an opinion or meaning in a frame that is easily understood.

\section{Definition of Political Cartoons}

The definition of cartoon was developed to be a preliminary sketch for a large canvas or fresco painting, or picture in mosaic. Gocek (1998:2), quoting Press (1981:62), defines cartoons as "pictures as the essence of truth, messages as to what ought to be done, and moods created through artistic techniques and allegorical imageries of how the viewers ought to feel over what is happening." In his efforts for reviewing the historical concepts, Harrison (1981:16) asserts that the word "cartoon" comes from the Italian and French words for "card" and "paper." Originally, a "cartoon" was a preliminary, full-sized sketch for a work of art that was done on paper. This sketch was then transferred to the wall, ceiling, or large canvas where the final work of art was to be completed. With the coming of the printing press, "cartoon" took on another meaning. It was a sketch which could be mass produced and an image which might be transmitted widely. 
Often, cartoons suggest humor which is reflected in the almost synonymous use of the words "comics" and "funnies". But today, the comics sometimes can be serious and hold more than one message. To simplify the idea of cartoons, Horn (1980:25) argues that drawings which contain complete thoughts can be called "cartoons." By the same token, the English cartoonist Sir David Low, as quoted by Harrison (1981:43), views cartoons as "drawings representational or symbolic that make satirical, witty or humorous points. They may or may not have captions and may comprise more than one panel." Certainly, the term "cartoon" conjures up connotations of fun or entertainment. Cartoons are simply drawings which distill first and distort second, and as Harrison (1981:80) asserts, they are "historically both political comment and humor." Cartoons may be effective rather than humorous as they may leave the viewers in a strong emotional position rather than smiles. Generally speaking, political cartoons often employ humor or irony to point out shortcomings or hypocrisies within the political system. Some do differentiate between editorial cartoons, which are daily published on the editorial page, and single panel political cartoons that make commentary on politics and policy.

Yet, many studies use the terms "political cartoons" and "editorial cartoons" interchangeably. They would generally appear on the opinion editorials "Op Ed" pages of a printed newspaper. In discussing the concept of cartoons, it is important to shed light on the distinction between cartoons and caricatures. Edwards (1997:9) doesn't differentiate between them because he believes that "the definition of political (editorial) cartoons as journalistic forms suggests something of their importance as objects of study from rhetorical or mass media communication perspectives." Moreover, Kenner (1997:3) also does not differentiate between the two terms as he explains that "political cartooning is synonymous with editorial cartooning." In reviewing the definitions of the two terms, Streicher (1967:31) argues that the difference between cartoons and caricatures is simply not very clear. In fact, caricature is inherent in all forms of cartooning. Today, "cartoons" and "caricatures" are used interchangeably. On the other hand, Hoffman (1958:45) notes that the term caricatures or cartoons, as they later became known, were born in Italy in the early sixteenth century, and both of them hold the same meaning in contemporary journalism. Edwards (1997:20) contends that caricatures were the immediate forerunner of contemporary political cartoons, and caricature remains a common element of invention employed by cartoonists.

Regarding the distinctive features of both terms, the American Heritage Dictionary (1991) differentiates between caricatures and cartoons as the former contains distinctive features that are deliberately exaggerated or distorted to produce comic or grotesque effect. Cartoons, on the other side, are pictorial satires or comments on a subject of public interest usually accompanied by words or caricatures.

\section{Historical Background of Political Cartoons in the Middle East}

The Middle East promptly started to employ this medium to condemn their own Westernizing persons and to ridicule and delegitimize the Western rulers. Their topics include the local myths, folktales and aesthetic forms that symbolized the burgeoning nationalist movements. The emergence of cartoons in the Middle East during the mid-nineteenth century coincided with the rise of Western influence. In this regard, Ceviker (1986:17) starts his search in the Ottoman Empire cartoons by observing the following:

The first Ottoman cartoon materialized in the journal Istanbul

in 1867, approximately thirty-five years after the publication

of the first Ottoman official gazette, Takvim-I Vekayi

(chronicle of events), and fifteen years after the publication of the

first humor gazette by an Ottoman Armenian,Hovsep Vartanyan. 
Turning to Egypt, Ya'qub Sannu was the first one in Egypt that published a humorous newspaper criticizing the West. The paper was named Al-Tankit Wa Altabkit "Joking and weeping". Although Arab journals appeared at the same time, the Egyptian press remained the major source of print for cartoons in the Arab world until 1925. Kishtainy (1985:73) shows that there were also other Arab cartoonists that emerged after this period such as Michael Tayas, who established the humor newspaper Kannas Al-Shawari "The Road Sweeper" in Iraq. In addition, there were also Khalid Kahhala from Syria and Bayram Al-Tunsi from Tunisia. Political cartoons in the Middle East became a point of arguments, creating new forms with new ideas. In fact, the popular visual representations and the heavily illustrated texts in the Middle Eastern newspapers reformed the aesthetic and visual foundation of cartoons. Mitchell (1989:22) claims that this empowerment through the reinterpretation of political cartoons has been successful in winning a few battles. Moreover, cartoons in the Middle East interpret images with a local trend and such cartoons change the embedded Western images and values. Political cartoons, on the other hand, in the Middle East began to focus on the use of visual signs to suggest the paradoxes of Ottoman Empire. While the majority of cartoon figures were male and female, cartoons played a set of highly significant roles in the satirical representation of revolutionary reality.

Moreover, political cartoons symbolized the concept of nation, its honor, and its vulnerability. Such political cartoons' figures represent the poles of modernity and tradition in the society. In short, political cartoons in the Middle East did not give a comprehensive picture of images of women in the Ottoman cartoons space. There are, in any given culture, complex and multiple options for representing woman. Ottoman cartoonists had at their disposal a multiplicity of women's images and cultural markers. They utilized these images and markers both to reflect and shape the Ottoman situation.

\section{Characteristics of Political Cartoons}

Since a long time, political cartoons have been used by newspapers and magazines as a method of criticizing the governments and political figures. They are unique combinations of pictorial/graphical editorials and creative commentaries, which allow cartoonists to make social commentaries beyond the written word.

Akande (2002:11) identifies five unique universal characteristics of political cartoons. First, different from other forms of the media, political cartoons employ humor in an attempt to make a political . Second, political cartoons provide a current commentary and critique of political events as they provide daily or weekly evaluations of important events, people, and issues. The narrative feature in political cartoons enhances the social criticism. Political cartoonists convey this in a clear, concise, and visually reinforcing manner. Third, political cartoons are considered as a form of diversion. To support his notion of diversion, Akande (2002:12) contends that they are cryptic, using as little written information as possible. The quantity of ink doesn't correlate to the power of the message. Even a total lack of information, as in blank page, can be a powerful message in masquerade the truth. A fourth distinguishing feature of political cartoons is that, they are sometimes amusing, but can simultaneously be emotionally devastating. Depending on the reader's perspective, cartoons can generate anger and outrage as well as laughs and funny sensations. Expressing and causing such responses is the basic goal of political cartoons because all the devices employed by the cartoonists are directed to that end. Although political cartoons are often perceived as a form of amusement, they are also a powerful medium for political discourse. A fifth feature of political cartoons is that they act as a means of establishing and evaluating political situations. Political cartoons can also establish political agendas by presenting judgments about politics that may affect a reader's beliefs and attitudes. Medhurst and De Sousa (1981:35) assert that political cartoons serve as important tools in identifying and perhaps establishing major values in society. Political cartoons make important contributions for setting up the public's and politicians' agendas. In this regard, they are capable of establishing and maintaining issues on the public arena. The last characteristic of political cartoons is that they are communication forces that connect the masses 
with political leaders. By the same token, Press (1981:62) observes that there are three basic elements of political cartoons. The first element includes the picture of reality that artists present to us as the essence of truth. Such cartoons show us what is happening in any society. the second element is a message which is sometimes implied. The third one is the artistic technique and allegorical imagery. In this element, the artist creates a mood that expresses feelings and senses over what is happening.

Current events, according to Press (1981:63), are used as window dressing to establish the validity of the cartoonist's assumptions about how life should be lived. Therefore, a cartoonist viewing student riots on campus in the late sixties could portray trashing of campus property as a result of the repressive and foolish rules established to stifle college youth. The impact of rhetorical functions of political cartoons on the readers was the focus of many researchers. Sullivan (1987:7) confirms that "the treatment of political cartoons as fictions suggest that the drawings may function as an archetypal example, giving us pretended insight." Readers must be able to make connections between the timely subject at hand and any literary or cultural allusion by which the cartoonists explain the situation figuratively. Thus, the reader is given an active role in interpreting the implicit message of the cartoonist. Edwards (1993:26-27) explains how cartoons function rhetorically as follows:

The cartoon's power lies in its intentionally persuasive nature as a form of satiric commentary, and in its use of myth to appeal to its audience and invite meaning.Although historically the cartoon's primary function has been seen as debunking, it also serves such rhetorical functions as framing, condensing and agenda setting according to communication scholars.

Many features of political cartoons attract the attention of communication experts, as Olaofe (1986:46) puts it, "perhaps the most glaring feature of all of them is simplicity. They are hand-drawn sketches containing short sentences and captions in simple."Such sketches are devoid of abstractions, and they are naturalistic in outlook. The drawings are made of simple illustrative lines with shading.

In addition, cartoons that are based on personal character traits might exaggerate or emphasize the personal features of the characters. Situational themes refer to idiosyncratic events which occur during the course of the events and have little meaning outside the timeframe in which they occur. A strong message or viewpoint is ineffective without an engaging method of presentation. Style is essential in any good cartoon. In this context, when we discuss the style of political cartoons, we should focus on the mode of expressions as distinct from the ideas presented. In this vein, Kenner (1987:37) presents three basic features for political cartoons which are: Humor, Drawing techniques, and Encapsulation.

The first feature, humor, is considered the fundamental feature of cartooning. The depiction of someone or something requires a humorous or a clever way that transmits the viewpoint of the cartoonist. To show the function of humor, Oliphant (1982:6) notes that "Nothing is better than humor as a vehicle for political thought. If the humor becomes an end in itself and the pacing is not varied according to the demands of the day, the message is horribly weakened." Typically, political cartoons are broadly humorous in ways that may be unacceptable in other forms of political commentary or reporting. Although Gombrich (1969) cautions against stressing humor as the central element in cartoons, humor does play a unique and central role in the way political cartoons communicate ideas. The second feature, drawing technique, confirms that a good message or viewpoint summed up in a humorous manner will be lost if the visual impact lacks style and clarity. Many cartoonists have stylized devices which they use to keep the audience interested, and to make 
certain that people understand the cartoons' meaning. Some cartoonists, as explained by Kenner (1987:40), "use captions and text to make their meaning clear, while others prefer a totally visual impact." The third feature, encapsulation, is also considered as an essential element in political cartoons.

Kenner (1987:40) argues that most cartoonists agree that cartoons are very time bound. They have about six to eight seconds to get a reader's attention, before the reader moves on to another section of the paper. Because of this temporal nature, cartoonists must be direct, clear and concise. They must encapsulate their ideas into a very simple form. Artistically, the cartoonists are constantly involved in creating images and relating these images to events in their environment. They are expected to present their images in simple forms, but such images shouldn't be so simple as to be misread by intelligent minds. To be able to attain this artistic goal, they need a high sense of creativity. Linguistically, the cartoonists are able to utilize words and expressions to describe particular incidents.

\section{Review of Previous Studies}

There have been several studies and researches that tackled comic cartoons, mainly political cartoons. Calogero and Mullen's (2008) study has tackled facial prominence in political cartoons, that of George W. Bush, as a function of involvement in war. The study revealed lower facial prominence in the portrayal of the target after the onset of war. These results were not a function of the topic of the cartoon and could not be explained by intentional efforts to derogate the target. The portrayal of a political leader as less powerful and less dominant after involvement in war is inconsistent with predictions for facial prominence effects.

Sani et al. (2012) investigated satire in Nigerian editorial cartoons through the linguistic elements used in these cartoons. Their study concluded that political cartoons are used to express opinions, construct valuable arguments and provide specific knowledge on contemporary social issues. The Nigerian cartoonists specifically use language to construct satire as a means that could be used perhaps to initiating positive social and political reforms in Nigeria. Nigerian cartoonists use interjections frequently in the cartoon written texts to create satirical impressions about political leaders, because interjections are used to express a strong emotions or feelings.

Bal et al. (2009) investigated the editorial caricatures depicting Jacob Zuma, the president of South Africa, and how the cartoon both played on and affected his political image and brand. The cartoon directly questioned Zuma's claims of discrimination by the justice system. The cartoonist (Zapiro) was able to use the cartoon to further solidify Zuma's image as an embattled yet contentious and divisive leader. The authors found that the Zapiro cartoon was immensely controversial. The controversy arose from the fact that it is so graphic, making it even more emotive than written criticism.

Illerbrun (2000) studied the political cartoons in Japanese newspapers from the rise of press to the mid-1990. He found that the graphic expression has long been an important part of Japanese society. From the earliest graffiti-like images to the souvenir Ötsu-e to the action-packed manga periodicals prevalent today, the course of Japanese history is limned by pictures. Also, he maintained that political cartoons had its complications, as these political cartoons were capable of conveying a very personal message, one that could be interpreted uniformly but with great nuance.

\section{The Cartoon Analysis}

The most prominent themes elaborated on in Iraqi political cartoons are financial and administrative corruption, power abuse, government promises and procrastination, electricity failure, and the like. The present paper tackles political cartoons in Iraqi print papers as from 2005 to the present. The source of data is six cartoons gathered from Iraqi social media sites. The analysis of the data follows Kress and Van Leeuwen (2006)approach. 


\subsection{Government Promises}

Government promises are a common theme in political cartoons in newspapers, especially the pledges and promises given by the government from time to time. Any government in the world launches its electoral platform with promises to boost social, economic and cultural improvement of the public conditions. Editorial cartoons often attempt to unfold the emptiness of such promises by showing the mere promises on the part of the government.

\section{Cartoon 1}

http://www.dreams-

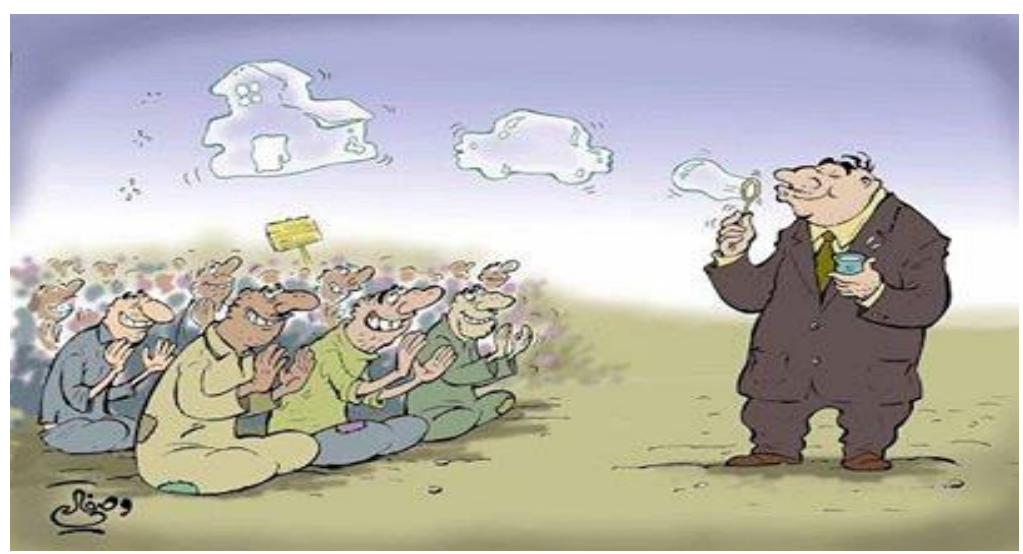

image.com/showthread.php?t=54550

In this cartoon, a government official is blowing off balloons before a group of audience. The balloons stand for the wishes and demands of the public, such as housing, jobs, goods,..etc. These airy promises are well received by the public which is clear in their clapping, and therefore they are happy that their demands are considered by the government. The paradox underlying such cartoons shows that cartoonists find fault with the government promises when these promises are in vain. Another area unveiled by this Fig. is the attitude of the government, one which is reflected in the mood of the official having standing firm and satisfied. The Iraqi citizens are made invisible and for the most part that is how they are portrayed in the cartoons - with barely a voice.

\subsection{Procrastination and Postponing}

Procrastination is a manipulative tactic used by certain people under certain conditions to communicate some goals. Political cartoons have always been critical of procrastination especially when it is originated by government officials or figures. Government officials tend to postpone or lay off actions or practices for several reasons, as when a head of state pledges to launch projects, but later on no single project is achieved. Such tactic takes longer, if not unforeseeable, prospects. Chakraborty (2016:62) argues "that procrastination and equivocation can be political strategies to avoid exigencies in the state. The political statesmanship lies in understanding the dynamics of power related to voluntary inaction rather than to violent action."

\section{Cartoon 2}

http://www.sarapress.com

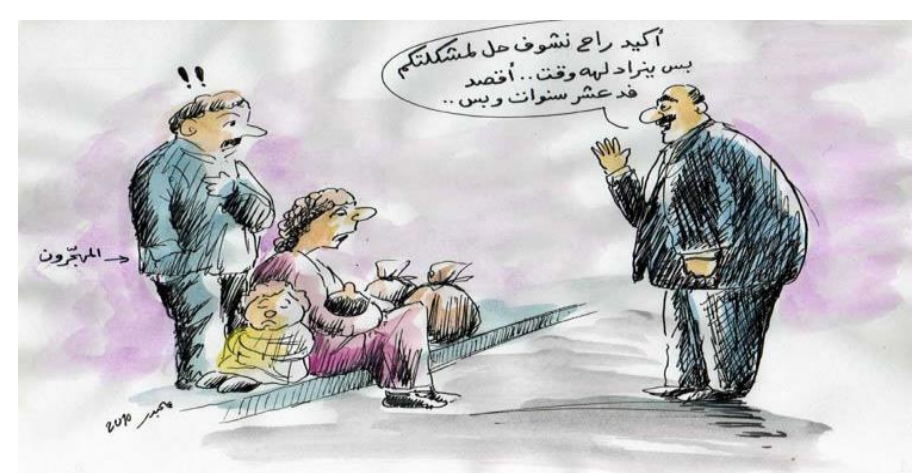


In this cartoon, a government official promises a street-bound homeless or displaced family that their existing conditions will come to end, weighing that their problems may take months or years to end. The verbal or lexical element used in this Fig. is significant too, for the official uses certainty in his promises أكيد. The official's promise reads "Surely we will find a solution for your problem but this will take some time.....I mean like ten years"

\section{Cartoon 3}

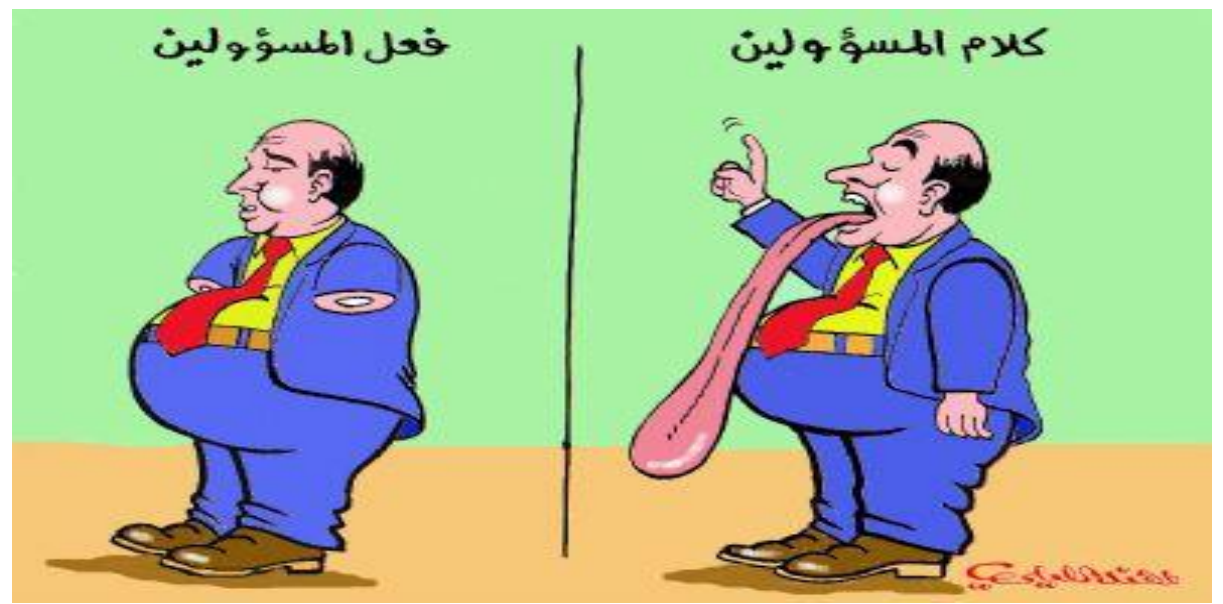

http:// www.alghadpress.com

This cartoon has two panels that represent the state of the politicians in Iraq. The right panel is entitled as "politicians' words", and the left side is entitled "politicians' acts." The right panel depicts the political figure with along tongue and a tall raising hand, while the left one depicts him as an armless figure. The humor occurs because of the cartoonist's employment of the Iraqi politicians to reflect his message about the contradiction between their verbal and the practical actions. In other words, those officials are giving promises which lack any effective or tangible action.

In this two-paneled cartoon, the scene-to-scene transition is offered here by presenting two framed images that are entitled "politicians' words and politicians' actions." This cartoon represents two different scenes that are related to Iraqi politicians. These two scenes show a strong reader involvement because of the close-up view of the character, and the cartoonist's choice to depict the message.

\subsection{Corruption and Financial Situation}

Corruption and financial situation was also a prominent theme in editorial cartoons. Corruption and financial affairs are still the most common area of cartooning when it comes to governments and countries. Corruption, the most fashionable in media and press, is considered a dangerous threat to governments and official policies.

\section{Cartoon 4}

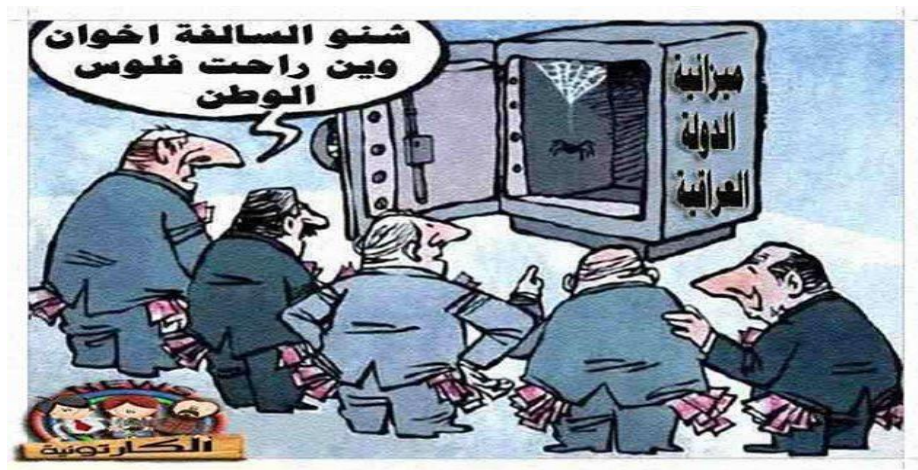

https://www.malaysia29.com/t138278.html 
This cartoon shows a number of politicians looking at an empty safe branded as "Budget of Iraq" with one of them wondering "What is going on fellows? Where are the nation's funds"? Denotatively, this cartoon represents Iraqi annual deficit budget and the manner at which it is presented. The cartoon comments on politicians' implementation of the budgeting system. Ideally, a budget is stolen by the politicians themselves, but they pretend as if they don't know where the budget has gone as shown on the cartoon. Thus, one can understand from the speech balloon that one of the politicians pretends as if they don't know where the budget has gone, although all their pockets fill with the budget stolen money.

However, connotatively, the cartoon has demonstrated how the budget is stolen by some of the bad officials in the government, which considers a clear sign of economic instability in Iraq. From the depiction, the cartoonist tries to reflect how serious the corruption in Iraq has become, and many analysts say that official corruption, more than any other factors, represents the root cause of poverty in Iraq.

\section{Cartoon 5}

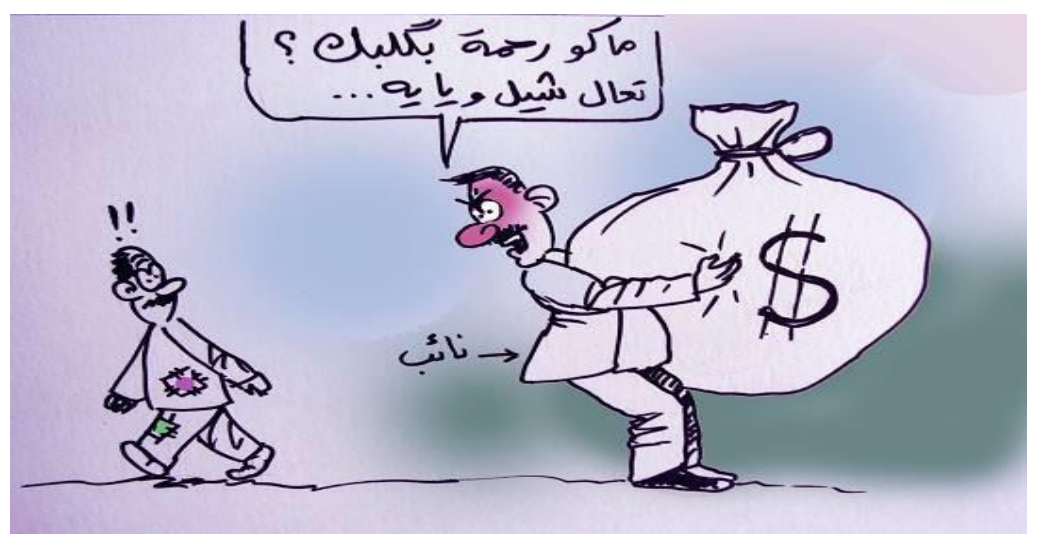

http://www.ishtartv.com/viewarticle,53974,cari.html

The denotation of this cartoon refers to one of the Parliament members who is carrying a huge container full of funds labeled " $\$$ ". On the far side is a pictorial image of a passer-by who is dressed like a pauper. His clothes are slack and he has a number of patches over what were seemingly gaping holes. The eyes of the MP, when he addresses the poor man, are opened in aggressive way to reflect his power. However, the poor man is portrayed with a disappointed and shocked look on his face.

The cartoonist mocks and criticizes the positions of some Parliament members as the cause of poverty in Iraq. It unveils how some MPs acquire funds by taking over the public or state funds. While the MP in this Fig. is well satisfied with the action he has taken, the man walking past him is astonished by this action.

\section{Cartoon 6}

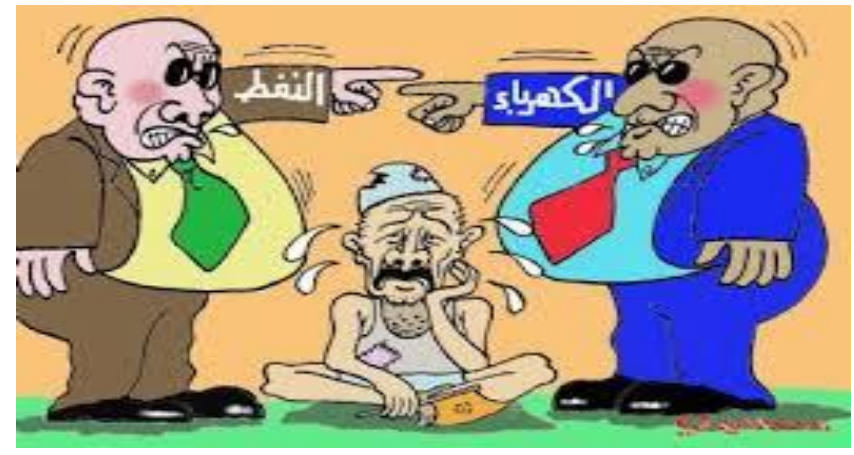

http://ahlaalsalawat.montadarabi.com/t2631-topic 
In this cartoon, three characters are presented. The man on the right

represents an official of electricity Ministry in Iraq. The other man on the left represents an official of Oil Ministry. The cartoon denotatively refers to the officials of these two Ministries as responsible for generating and distributing electricity in Iraq.

They have their fight on top of the Iraqi citizen, who has been trampled by the others. They blame each other on who is the responsible of the electricity failure in Iraq. However, their fight results in difficulty knowing who is the real responsible one. Each one blames the other for ignoring the Iraqi citizen who does not have a voice compared with them.

Many signifiers are presented in this cartoon in order to convey the cartoonist's message. The Evidence of these two characters' affluence is provided by the use of their bulging stomachs, formal suits and dark glasses which refer to how the political figures live in luxuriously at the detriment of the Iraqi citizen who suffers from the hot of summer without electricity, in addition to the poverty and destitution.

This cartoon highlights one of the main issues that Iraqi people suffer from, it is the electricity failure. The cartoon depicts the government's inability to generate and distribute electricity in the entire country. This cartoon illustrates more on how Iraqi citizens got used to several hours of darkness.

\section{Conclusions}

This research contributes an understanding of how The Iraqi political cartoons reflect the local events that exist in our daily life. The Iraqi cartoonists can use the visual and verbal modes in order to convey the messages that they want to transmit to their readers. On the other hand, the analysis of the selected political cartoons reflects the stance of the cartoonists over the characters and situation they portray, trying to recover the main features of them.

The Iraqi political cartoons play important roles in framing and determining the public feeling towards the current events. They may be closer and simpler to explain the political situation than the political writers do. However, the most common themes covered by Iraqi political cartoons are financial and administrative corruption, power abuse, government promises, procrastination, electricity failure and government's careless and inaction.

Based on the previous discussions, it is obvious that the Iraqi cartoonists employ humor in an attempt not only to amuse the readers, but to make change in the society for the better. Moreover, they can sometimes generate anger and outrage as well as funny sensations.

\section{References}

Akande, O. (2002). A semiotic analysis of political cartoons: A case study of

Nigeria. Ph.D Dissertation, University of Oklahoma.

Bal, A.S., Pitt, L., Berthon, P., and DesAutels, P. (2009).“Caricatures, cartoons, spoofs and satires: Political brands as butts" Journal of Public Affairs, 9 (229-237).

Calogero, R.M. and Mullen, B. (2008). “About face: Facial prominence of George W. Bush in political cartoons as a function of war" The Leadership Quarterly, 19 (107-116).

Ceviker, T. (1986). Gelişim Sürecinde Türk Karikatürü (Turkish Cartoon

in Development Process). Istanbul: Adam Yayınları.

Chakraborty, N.(2016:62)."Politics of Equivocation and Deferral: Queen

Elizabeth I and the Execution of Queen Mary of Scotland" 
Rupkatha Journal on Interdisciplinary Studies in Humanities, (62-69).

Edwards, J. L. (1997). Political cartoons in the 1988 presidential campaign:

Image, metaphor, and narrative. London: Routledge.

Gocek, F. M. (1998). Political Cartoons in the Middle East. Princeton:

Markus Wiener Publishers.

Gombrich, E. H. (1969). Art and Illusion: A study in the Psychology of

Pictorial Representation. Princeton: Princeton University Press.

Harrison, R.P. (1981). The cartoon: Communication to the Quick. London:

Sage Publications.

Hoffman, W. (1958). La Caricature de Vin a Picasso. Paris: Editions

Aimry Somogy.

Horn, M. (1980). The World Encyclopedia of Cartoons. New York:

Chelsea House.

Illerbrun, K. (2000). The Japanese Political Cartoon: Development and

Decline. Master Thesis, University of Oxford.

Kishtainy, K. (1985). Arab Political Humor. London: Quartet Books.

Kenner, M.J. (1987). Political Cartoons and synecdoche: A Rhetorical

Analysis of the 1984 Presidential Campaign. Ph.D Dissertation,

University of Massachusetts .

Kenner, (1997). “ The Exploding Duck and the Other Primal Tales” Normal

Review, 12 (113-126).

Kress, G. and Leeuwen, T. (2006). Reading images: The grammar of visual

design. London and New York: Rutledge. Second Edition.

Medhurst,M. J and DeSousa, M. A.(1981). Political cartoons as rhetorical

forms: A taxonomy of graphic discourse. Communication

Monographs .

Mitchell, T. (1989). Culture Across Borders. Middle East Report 19/4:4-6.47.

Oliphant, P. (1982). "Quintessential Cartooning: The Political Art of the Pat

Oliphant". The political Quarterly, 1: 4-8.

Press, C. (1981). The Political Cartoon. Rutherford: New Jersey: Fairleigh

Dickinson University Press.

Sani, I., Abdullah, M.H., Ali, A.M., and Abdullah, F.S. (2012). "Linguistic analysis on the construction of satire in Nigerian political cartoons:

The example of newspaper cartoons" Journal of Media and

Communication Studies, 4:3 (52-59).

Streicher, L. (1967). "On a Theory of Political Caricature". Comparative

Studies in Society and History, 427- 445.

Sullivan, J. (1987). "Reading Political Cartoons". Unpublished Paper, Speech

Communication Association, Washington. D.C.

The American Heritage Dictionary (1991). Boston, MA: Houhton Mifflin. 